\title{
Foreign material in a maxillary sinus as a complication of root canal treatment: a case report
}

\author{
Nesrin Saruhan, Adnan Kılınç, Tahsin Tepecik, Ümit Ertaş \\ Department of Oral and Maxillofacial Surgery, Ataturk University Faculty of Dentistry, Erzurum, Turkey
}

The roots of maxillary teeth proximity to maxillary sinuses can lead to overfilling of endodontic materials to maxillary sinuses accidentally. In some cases, overfilling of endodontic materials require surgical procedures. Foreign endodontic material within the maxillary sinus after endodontic treatment on extracted tooth \#15 is presented in this case report. Foreign material inside the maxillary sinus was removed successfully by Caldwell-Luc operation. Postoperative healing was uneventfully.

Keywords: Caldwell-Luc operation; foreign material; maxillary sinus.

$\mathrm{E}$ ndodontic infections of posterior maxillary teeth sometimes spread to the maxillary sinus, generating severe complications. ${ }^{[1]}$ In some cases, the roots of the posterior maxillary teeth come into close contact with maxillary sinuses. They may contact with only the cortical wall of the floor of sinuses, or even project into the maxillary sinus so that teeth apices are only covered by Schneiderian membrane. Such anatomic variations can lead to the establishment of an oro-antral communication during root canal treatment. As a result, possible complications such as displacement of endodontic materials into the maxillary sinus may develop. ${ }^{[2]}$ In this case report, we present a patient complaining about the pain and swelling in her right maxillary sinus area. Radiographic examination showed a dense foreign material in maxillary sinus and the patient history revealed previous endodontic theraphy and extraction of the tooth \#15 because of the discomfort and pain. Those findings were compatible with the scenario of iatrogenic complication of the root canal treatment; displacement of the filling material into the maxillary sinuses.

\section{Case report}

26 year-old-female patient visited our department complaining about the pain on the right side on the face and on the tooth \#15. The patient reported that these symptoms had started after the related tooth had undergone endodontic theraphy. Panoramic and periapical radiographs were taken as a part of dental examination and it showed a radiodense foreign material in the right maxillary sinus (Fig. la and b). The foreign material was observed to have spread to maxillary sinus wall away from the region of the previously extracted tooth 15 . The patient was told about the results of examination and the need for additional surgical treatment. The foreign material was removed through an antrostomy in the lateral sinus wall (Fig. $2 \mathrm{a}$ and $b$ ). The sinus was irrigated with a physiological saline solution. The flap was then sutured into its original position. The surgical site was uneventful in postoperative 10 day and any signs for oro-antral communication or sinus infection were seen.

Correspondence: Dr. Nesrin Saruhan. Atatürk Üniversitesi Diş Hekimliği Fakültesi,

Ağız Diş ve Çene Cerrahisi Anabilim Dalı, Erzurum, Turkey.

Tel: +90 442 - 2311801 e-mail:dt_nesrin@yahoo.com

Submitted: January 24, 2016 Accepted: April 05, 2016 

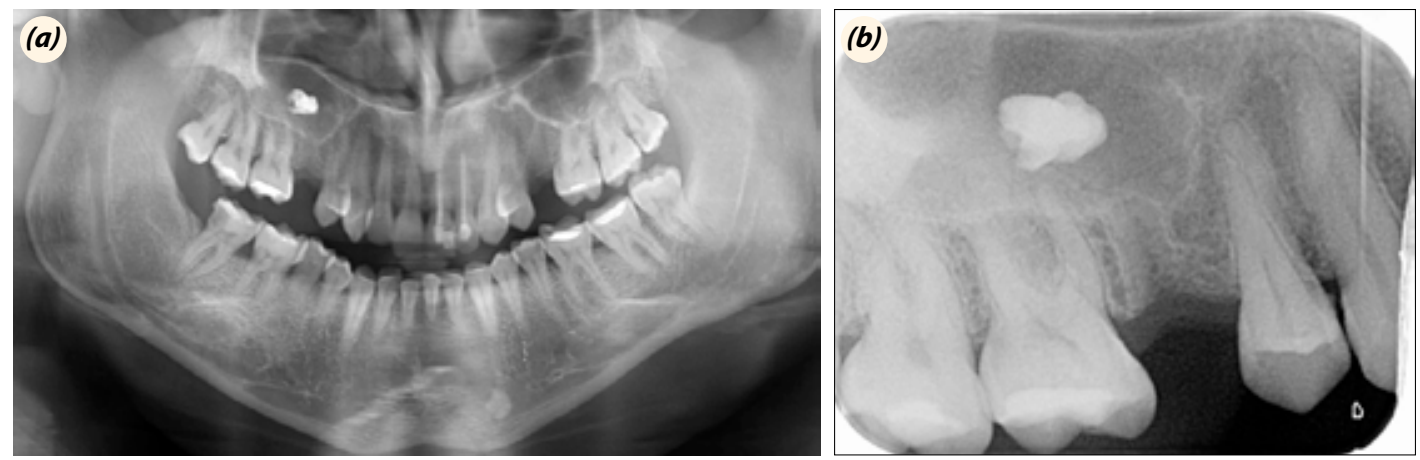

Fig. 1. (a) Orthopantomography showing radiopacity of the right maxillary sinus. (b) Foreign material was seen in periapical radiography.
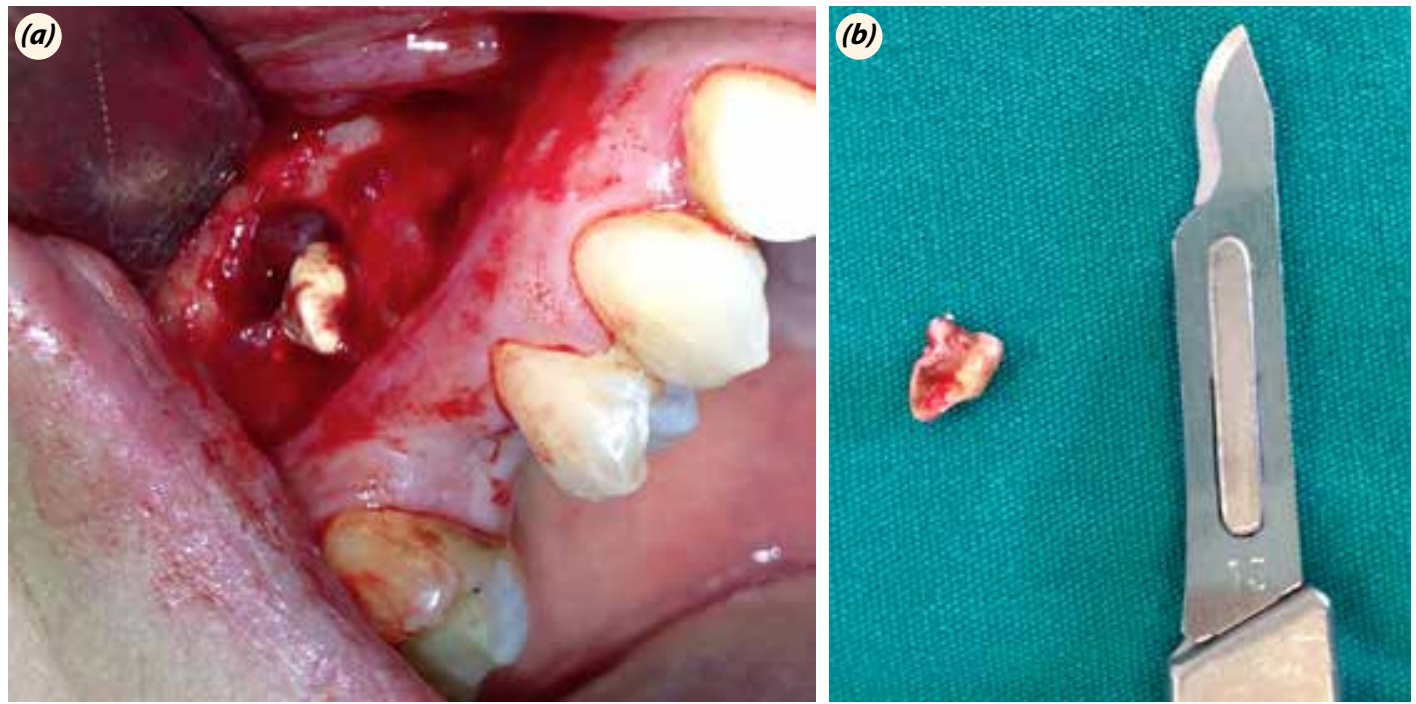

Fig. 2. (a) Foreign material was seen in maxillary sinus intraoperatively. (b) Removal of specimen was seen.

\section{Discussion}

The bone of the maxillary sinus floor can be very thin and in some cases the roots of the posterior teeth project through this bone. In these cases the root tips are surrounded by only Schneiderian membrane. ${ }^{[3]}$ Thus, a tooth itself, fractured roots of teeth, dental implants, dental burs, fractured files can be found in a maxillary sinus as a result of series of complications during different treatment procedures. ${ }^{[4,5]}$ Great care must be taken during dental treatments especially endodontic treatments, not to inadvertently introduce foreign material into the antrum.

Extrusion of endodontic filling material which is an endodontic complication, is seen as a result of over-instrumentation during root canal treatment. ${ }^{[2,6]}$ Over-instrumentation and extrusion of endodontic filling materials can cause maxillary sinus complications. ${ }^{[5,7]}$ As a result of these complications, chronic sinusitis, chemical irritations of ciliated mucosa and/or Aspergillus infections of paranasal sinuses may develop. ${ }^{[8,9]}$ Killey and Kay noted that although sinusitis was a common occurrence after entry of a foreign material into the antrum, the onset of change in the antral lining may be delayed for months or even years. ${ }^{[10]}$ Possibly if a 'step back' technique in preparing the root canal and the placement of an initial principal point followed by further additional points using lateral condensation had been utilized then the root filling material would not have been displaced through the apex in our case.

A minimal sealer-extrusion should bring a symptomfree prognosis, with a mild inflammatory tissue reaction after the first obturation. Patients should be informed about possible complications involving removal of root canal filling materials with sinus surgery. Additionally, panoramic radiographic examination is the most important tool to detect massive extrusion of endodontic materials to the maxillary sinus. ${ }^{[11]}$

It is generally accepted that removal of foreign material with surgically to prevent acute or chronic sinusitis, mucosal cysts, to prevent or persistent oro-antral communication, antrolit. ${ }^{[5]}$ 
Conflict of interest: None declared.

\section{References}

1. Nimigean VR, Nimigean V, Maru N, Andressakis D, Balatsouras DG, Danielidis V. The maxillary sinus and its endodontic implications: clinical study and review. B-ENT 2006;2:167-75.

2. Yaltirik M, Koçak Berberoglu H, Koray M, Dulger O, Yildirim S, Aydil BA. Orbital pain and headache secondary to overfilling of a root canal. J Endod 2003;29:771-2.

3. Gray H, Bannister LH, Berry MM, Williams PL. Gray's Anatomy. 38th ed. London: Churchill Livingstone; 1995.

4. Dimitrakopoulos I, Papadaki M. Foreign body in the maxillary sinus: report of an unusual case. Quintessence Int 2008;39:698-701.

5. Liston PN, Walters RF. Foreign bodies in the maxillary antrum: a case report. Aust Dent J 2002;47:344-6. Crossef

6. Khongkhunthian P, Reichart PA. Aspergillosis of the maxillary sinus as a complication of overfilling root canal material into the sinus: report of two cases. J Endod 2001;27:476-8. Crossref

7. Yamaguchi K, Matsunaga T, Hayashi Y. Gross extrusion of endodontic obturation materials into the maxillary sinus: a case report. Oral Surg Oral Med Oral Pathol Oral Radiol Endod 2007;104:131-4. Crossref

8. Pagella F, Emanuelli E, Castelnuovo P. Endoscopic extraction of a metal foreign body from the maxillary sinus. Laryngoscope 1999;109:339-42. Crossref

9. Legent F, Billet J, Beauvillain C, Bonnet J, Miegeville M. The role of dental canal fillings in the development of Aspergillus sinusitis. A report of 85 cases. Arch Otorhinolaryngol 1989;246:318-20 Crossef

10. Killey H, Kay L. Possible sequelae when a tooth or root is dislodged into the maxillary sinus. Br Dent J 1964;116:73.

11. Neaverth EJ. Disabling complications following inadvertent overextension of a root canal filling material. J Endod 1989;15:135-9. Crossref 